\title{
Evaluation of Virulence to Adlays of Korean Isolates of Bipolaris coicis Using a Disease Rating Scale
}

\author{
Seog Won Chang, Northern Agricultural Research Station, Gyeonggido Agricultural Research and Extension Ser- \\ vices, Yonchon 486-833, Korea; and Byung Kook Hwang, Laboratory of Molecular Plant Pathology, College of \\ Life and Environmental Sciences, Korea University, Seoul 136-701, Korea
}

\begin{abstract}
Chang, S. W., and Hwang, B. K. 2003. Evaluation of virulence to adlays of Korean isolates of Bipolaris coicis using a disease rating scale. Plant Dis. 87:726-731.

The virulence of 33 isolates of Bipolaris coicis from diverse geographic origins in Korea was evaluated on six adlay cultivars or lines under controlled environmental conditions. To evaluate infection levels of $B$. coicis isolates in adlay plants, a 10-class disease rating scale was developed based on the qualitative and quantitative differences of lesions on adlay leaves infected. There were significant differences in virulence among isolates of B. coicis, although the differences were quantitative rather than qualitative. Significant differences also were observed among cultivar-isolate interactions in the analysis of variance. All isolates of B. coicis, except KG-9515, were pathogenic on adlay plants. BC-20136, the most virulent isolate, was capable of causing highly susceptible reactions on the adlay cultivars or lines. Significant differences in levels of resistance were found among six adlay cultivars or lines tested. The disease rating scale may be a reliable criterion to evaluate a large number of adlays for resistance to leaf blight or B. coicis isolates for virulence to adlays.
\end{abstract}

Bipolaris coicis (Nisikado) Shoemaker (teleomorph: Cochliobolus nisikadoi (Tsuda, Ueyama \& Nishihara) Alcorn) is one of the most widespread and destructive foliar pathogens, occurring in growing areas of adlay or Job's tears (Coix lacryma-jobi L. var. ma-yuen (Romanet) Stapf.); that is, Japan and Korea $(10,25)$. The pathogen infects adlay, corn, wheat, barley, and Tiger grass (Thysanolaena maxima) $(11,19,21)$. The symptoms on adlay are leaf blight and seed rot $(1,11)$. Adlay seed are used ornamentally, and as a medicinal and cereal food in many countries $(10,17)$.

Leaf blight is capable of causing significant yield and seed quality losses in adlay production (2). Infection of adlay by $B$. coicis is influenced by the humidity period and host genotypes $(1,2)$. Additional factors that can influence severity of leaf blight on adlay plants include the age of adlay foliage, inoculum density of $B$. coicis, and levels of residue left by different tillage systems $(2,9,17)$. In particular, the occurrence of epidemics of leaf blight in adlay-growing areas has been attributed to changes in cultural practices, including shifts from conventional tillage to reduced tillage, shorter rotations, continuous adlay

Corresponding author: B. K. Hwang

E-mail: bkhwang@korea.ac.kr

Accepted for publication 28 January 2003.

Publication no. D-2003-0414-03R

(C) 2003 The American Phytopathological Society cultivation, and the culture of highly susceptible cultivars $(9,17)$.

Variation of pathogenicity in B. coicis was first reported by Kim et al. (12). Differences in virulence of $B$. coicis isolates from different geographical areas are well documented $(11,12)$. More recently, Lee (18) reported that B. coicis isolates were divided into two groups of white and brown types that were identical in size and shape of conidia, but differed in growth rate, sporulation, pathogenicity, random amplified polymorphic DNA banding patterns, and presence of double-stranded RNA.

Although the use of fungicides can be effective in reducing leaf blight development in fields, the most effective and environmentally sound means of control is considered to be the use of resistant cultivars $(1,3)$. In Korea, however, there are no commercial adlay cultivars that are highly resistant to the leaf blight pathogen in the field (1). The adlay breeding program of the Northern Agricultural Research Station (NARS) in Korea has placed emphasis on selecting adlay cultivars resistant to leaf blight caused by B. coicis. Greenhouse evaluation may be a useful technique to screen adlay cultivars or lines for resistance to leaf blight. The greenhouse screening could provide a good indication of a prospective reaction of adlay cultivars or lines for resistance to leaf blight in the field. The use of seedling plants in the greenhouse is justified by greater efficiency in terms of space and time.

Effective screening techniques are important to differentiate between resistant and susceptible cultivars $(6,26)$. To classify the disease reactions of adlay cultivars or lines for breeding purposes or studies on $B$. coicis-adlay interaction, it is important to develop a rating method that fully describes the range of infection responses. A quantitative assessment may be more effective than a qualitative one for detecting and analyzing relatively small differences in the disease resistance of adlay cultivars to leaf blight. The proportion of diseased leaf area is considered to be associated with quantitative disease reactions (22). However, the assessment technique may be more effective when based on both the qualitative and quantitative attributes of the disease reactions $(4,8)$. Tekauz $(23)$ proposed a scale to classify barley reactions at the seedling stage to net blotch caused by Pyrenophora teres. This scale has been used by numerous workers and, apparently, is efficient to screen a large number of breeding lines of barley for resistance to net blotch.

The objectives of this study were to develop a comprehensive disease rating scale based on the qualitative and quantitative differences of lesions observed on adlay seedling plants infected with $B$. coicis, and to evaluate, under controlled environmental conditions, the virulence of 33 isolates of $B$. coicis collected from diverse geographic origins in different years.

\section{MATERIALS AND METHODS}

Fungus and plant. A total of 33 isolates of $B$. coicis were collected from leaf blight-infected adlay plants in various adlay-growing regions of Korea between 1995 and 2000 (Table 1). Infected leaves with leaf blight lesions were cut into 2-cmlong pieces, wetted in $95 \%$ ethanol for 10 $\mathrm{s}$, and surface sterilized in a $2 \%$ sodium hypochlorite solution for $90 \mathrm{~s}$. The leaf tissue segments were rinsed in sterile distilled water, blotted on a sterile filter paper to remove excess water, and aseptically transferred to the plates containing $2 \%$ water agar. Sporulation of B. coicis usually occurred on the infected leaf tissues within 3 days after being transferred. Single conidia were transferred from the leaf tissue to a second water agar plate, so that the germinability of the conidia could be verified. After incubation for 5 days, $1-\mathrm{cm}$ diameter disks of mycelium and agar were cut from the young mycelial colonies growing near the sides of the plates. All the 
isolates of $B$. coicis identified were stored on corn meal agar at $4{ }^{\circ} \mathrm{C}$ until used and transferred every 2 months to the same media.

The six adlay (Coix lacryma-jobi $\mathrm{L}$. var. ma-yuen (Romanet) Stapf) cultivars or lines of differing resistance to $B$. coicis were selected from 30 adlay cultivars or lines cultivated or bred in Korea (1). These lines differed in resistance to $B$. coicis, based on our data from preliminary field tests at Yonchon (1). The adlay lines Tsukuba B15 and Muzu were used as resistant checks, the cultivars Yulmu 1 and Yonchon had moderate resistance, and the lines Limgae and Huksuk 2 were included as susceptible checks. Heading dates of all adlay cultivars or lines are within 2 weeks of each other.

Inoculation procedures. Ten adlay plants of each cultivar or line were sown in plastic pots ( 5 by 15 by $10 \mathrm{~cm}$ ) containing a steam-sterilized soil mix of a commercial compost soil (peat moss:perite:vermiculite, $5: 3: 2, \mathrm{vol} / \mathrm{vol} / \mathrm{vol})$, sand and loam soil $(1: 1: 1, \mathrm{vol} / \mathrm{vol} / \mathrm{vol})$ in the greenhouse. Adlay plants were grown in a greenhouse at $25 \pm 3^{\circ} \mathrm{C}$. The basal fertilizer was applied at $0.16-0.16-0.1 \mathrm{~g}$ of actual N-P-K per pot.

The isolates of $B$. coicis were cultured on a corn meal agar at $25 \pm 1^{\circ} \mathrm{C}$ for 10 days, then sporulated under continuous

Table 1. Isolates of Bipolaris coicis from different areas of Korea tested for their virulence pattern on adlay cultivars or lines

\begin{tabular}{lcl}
\hline Isolate & Year collected & Geographic origin (location) \\
\hline KG 9512 & 1995 & Muzu \\
KG 9515 & 1995 & Youngdong \\
KG 9521 & 1995 & Muzu \\
BC-97005 & 1997 & Jangsu \\
BC-97006 & 1997 & Yonchon \\
BC-98011 & 1998 & Yonchon \\
BC-9889 & 1998 & Boun \\
BC-9894 & 1998 & Boun \\
BC-9895 & 1998 & Boun \\
BC-9896 & 1998 & Boun \\
BC-9937-2-1 & 1999 & Chongwon \\
BC-9937-2-2 & 1999 & Chongwon \\
BC-9939-1 & 1999 & Chongju \\
BC-9940 & 1999 & Yonchon \\
BC-9942 & 1999 & Yonchon \\
BC-9957 & Pajoo \\
BC-9960 & 1999 & Yonchon \\
BC-9973 & 1999 & Yonchon \\
BS-9978 & 1999 & Yonchon \\
BS-9979 & 1999 & Yonchon \\
BC-9985 & Pocheon \\
BC-9986 & 1999 & Pocheon \\
BC-9992 & 1999 & Pocheon \\
BC-9993 & Chongwon \\
BC-9998 & 1999 & Chongwon \\
BC-9999 & 1999 & Chongwon \\
BC-99100 & 1999 & Pocheon \\
BC-99101 & 1999 & Pajoo \\
BC-99102 & 1999 & Pocheon \\
BC-99103 & Pajoo \\
BC-20136 & 1999 & Yonchon \\
BC-20140 & 1999 & Yonchon \\
BC-20151 & 1999 & Yonchon \\
\hline
\end{tabular}

fluorescent light at $25 \pm 1{ }^{\circ} \mathrm{C}$ for $48 \mathrm{~h}$. Mycelial and conidial suspensions were prepared by gently scraping the agar surface in sterile water with a sterilized spatula and then filtering the mycelial and conidial suspensions through two layers of cheesecloth.

The conidial suspensions of $B$. coicis were adjusted to $10^{5}$ conidia $/ \mathrm{ml}$ using a hemacytometer. Plants were inoculated by using an atomizer to spray the conidial suspension containing $0.03 \%$ Tween 20 on the leaves of adlay plants at the two-leaf stage. The conidial inoculum was applied just until the beginning of runoff from the foliage.

Inoculated plants were placed in a moist chamber at $25 \pm 1{ }^{\circ} \mathrm{C}$. After incubation for $24 \mathrm{~h}$ in the moist chamber, the plastic pots, each containing 10 inoculated adlay plants, were transferred to a greenhouse maintained at $26 \pm 3^{\circ} \mathrm{C}$ for disease evaluation.

Disease severity assessment. Development of leaf blight on the second leaves of adlay seedling plants was assessed 7 days after inoculation, at which time the susceptible control (Huksuk 2) produced fully susceptible lesions, but tissue had not collapsed. Leaves exhibiting uniform lesion types were photographed to make color plates to aid in the classification of disease development. Leaf blight on adlay leaves were rated based on a 0 -to-9 scale (Table 2; Fig. 1). Class 0 was the highly resistant response in which no lesions are visible on leaves (Fig. 1). Classes 1 and 2 exhibited pinhead sized $(0.1$ to $1.0 \mathrm{~mm})$ or small $(1.0$ to $3.0 \mathrm{~mm}$ ), round to elliptical, dark-brown necrotic lesions on the leaves. Class 3 consisted of larger ( 3.0 to $5.0 \mathrm{~mm}$ ), round to elliptical, whitish-brown necrotic lesions. Classes 4 and 5 ranged from about 2 to $10 \%$ diseased leaf area covered with small chlorotic lesions. Classes 6, 7, 8, and 9 consisted of elongated white-yellowish lesions. Some lesions occasionally fused into larger, broader ones. Zones of the diffuse chlorosis usually extended along the leaf, often joining adjacent lesions. Further lesion expansion resulted in the coalescing of lesions and the blighting of

Table 2. Description of disease development on adlay seedling plants infected by Bipolaris coicis in greenhouse

\begin{tabular}{|c|c|c|}
\hline $\begin{array}{l}\text { Disease } \\
\text { rating scale }\end{array}$ & $\begin{array}{l}\text { Infection } \\
\text { type }^{b}\end{array}$ & Description of symptom development \\
\hline 0 & HR & No visible lesions. \\
\hline 1 & $\mathrm{R}$ & Dark-brown spots of pinhead (0.1-1.0 mm) size. \\
\hline 2 & $\mathrm{R}$ & Small $(1.0-3.0 \mathrm{~mm})$, round to elliptical, dark-brown necrotic lesions. \\
\hline 3 & MR & Larger $(3.0-5.0 \mathrm{~mm})$, round to elliptical, whitish-brown, necrotic lesions. \\
\hline 4 & MS & $2-5 \%$ of diseased leaf area with small, chlorotic lesions. \\
\hline 5 & $\mathrm{~S}$ & $5-10 \%$ of diseased leaf area with small diffuse, chlorotic lesions. \\
\hline 6 & $\mathrm{~S}$ & $10-15 \%$ of diseased leaf area with white-yellowish lesions. Some lesions occasionally fuse into a broad one. \\
\hline 7 & $\mathrm{~S}$ & $\begin{array}{l}15-25 \% \text { of diseased leaf area with elongated white-yellowish lesions. The diffuse chlorosis usually extends along } \\
\text { the leaf, often joining adjacent lesions. }\end{array}$ \\
\hline 8 & S & $\begin{array}{l}25-50 \% \text { of diseased leaf area with elongated white-yellowish lesions. The diffuse chlorosis extends along the leaf, } \\
\text { often joining adjacent lesions. The joining lesions typically run parallel to leaf veins. }\end{array}$ \\
\hline 9 & S & $\begin{array}{l}\text { More than } 50 \% \text { of diseased leaf area with elongated white-brownish lesions. Further lesion expansion results in the } \\
\text { coalescing of lesions and the blighting of entire leaves. }\end{array}$ \\
\hline
\end{tabular}

\footnotetext{
${ }^{a}$ Disease ratings are based on the type and relative size of lesions observed on the second leaves of adlay seedling plants.

${ }^{\mathrm{b}}$ HR: highly resistant, R: resistant, MR: moderately resistant, MS: moderately susceptible, S: susceptible.
} 


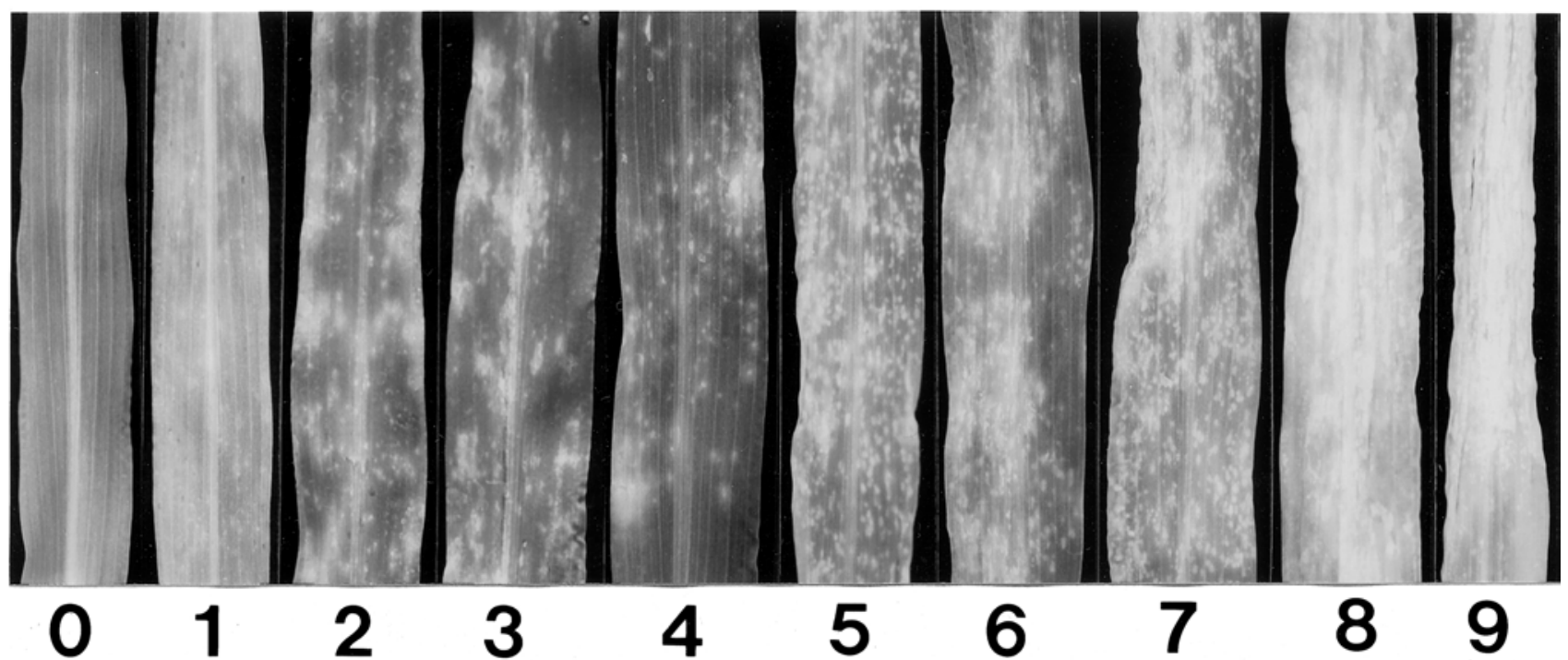

Fig. 1. Disease rating scale for adlay seedling plants infected with Bipolaris coicis. Disease rating scales are based on the type and relative size of lesions observed on the second leaves of adlay seedlings 7 days after inoculation. The 10-class disease rating scale is classified into five general categories of highly resistant (0), resistant (1-2), moderately resistant (3), moderately susceptible (4), and susceptible (5-9) responses. Class 0 is the immune response in which no lesions were observed. Classes 1 and 2 consist of pinhead-sized or small, dark-brown necrotic lesions. Class 3 consists of larger round to elliptical, whitish-brown necrotic lesions. Classes 4 and 5 consist of 2 to $10 \%$ of diseased leaf area with elliptical to ovate, chlorotic lesions. Classes 6, 7, 8, and 9 represent 10 to $100 \%$ of diseased leaf area with elongated, white-yellowish lesions. The diffuse chlorosis usually extended along the leaf, joining adjacent lesions. The lesions ran parallel to leaf veins. Further lesion expansion resulted in the coalescing of lesions and the blighting of entire leaf. Differentiation between classes 6 and 9 is based on the difference in diseased leaf area. The leaves depicted in the plates are $1.2 \times$ their original sizes.

Table 3. Ratings of disease development on the second leaves of six adlay cultivars or lines inoculated by foliar spray with 33 Bipolaris coicis isolates at the two-leaf stage

\begin{tabular}{|c|c|c|c|c|c|c|}
\hline \multirow[b]{2}{*}{ Isolate } & \multicolumn{6}{|c|}{ Disease rating scale $^{a}$} \\
\hline & Tsukuba B15 & Muzu & Yulmu 1 & Yonchon & Limgae & Huksuk 2 \\
\hline BC-98011 & $6(S)$ & $6(\mathrm{~S})$ & $7(S)$ & $7(S)$ & $8(S)$ & $9(\mathrm{~S})$ \\
\hline BC-9986 & $5(\mathrm{~S})$ & $6(\mathrm{~S})$ & $8(S)$ & $9(\mathrm{~S})$ & $7(S)$ & $7(S)$ \\
\hline BC-9894 & $7(S)$ & $7(\mathrm{~S})$ & $8(\mathrm{~S})$ & $6(\mathrm{~S})$ & $7(\mathrm{~S})$ & $8(S)$ \\
\hline BC-9985 & $6(\mathrm{~S})$ & $7(\mathrm{~S})$ & $8(S)$ & $8(S)$ & $7(S)$ & $7(\mathrm{~S})$ \\
\hline BC-9895 & $5(\mathrm{~S})$ & $6(\mathrm{~S})$ & $6(\mathrm{~S})$ & $6(\mathrm{~S})$ & $7(\mathrm{~S})$ & $9(\mathrm{~S})$ \\
\hline BC-97006 & $5(\mathrm{~S})$ & $6(S)$ & $6(S)$ & $7(S)$ & $8(\mathrm{~S})$ & $8(\mathrm{~S})$ \\
\hline ВC-99101 & $6(\mathrm{~S})$ & $7(\mathrm{~S})$ & $7(\mathrm{~S})$ & $8(S)$ & $8(\mathrm{~S})$ & $7(S)$ \\
\hline BC-99103 & 7 (S) & $7(\mathrm{~S})$ & $7(\mathrm{~S})$ & $7(\mathrm{~S})$ & $6(\mathrm{~S})$ & $7(\mathrm{~S})$ \\
\hline ВC-9889 & 4 (MS) & $5(\mathrm{~S})$ & $5(\mathrm{~S})$ & $5(\mathrm{~S})$ & $5(\mathrm{~S})$ & $9(\mathrm{~S})$ \\
\hline BC-9973 & $5(\mathrm{~S})$ & $6(\mathrm{~S})$ & $6(\mathrm{~S})$ & $6(\mathrm{~S})$ & $8(\mathrm{~S})$ & $7(\mathrm{~S})$ \\
\hline BC-9940 & $5(\mathrm{~S})$ & $7(\mathrm{~S})$ & $6(S)$ & $7(S)$ & $7(\mathrm{~S})$ & $5(\mathrm{~S})$ \\
\hline BC-9957 & 4 (MS) & $5(\mathrm{~S})$ & $6(\mathrm{~S})$ & $6(\mathrm{~S})$ & $6(\mathrm{~S})$ & $8(\mathrm{~S})$ \\
\hline BC-20136 & $5(\mathrm{~S})$ & $5(\mathrm{~S})$ & $6(S)$ & $7(\mathrm{~S})$ & $7(S)$ & $7(\mathrm{~S})$ \\
\hline ВC-99100 & $5(\mathrm{~S})$ & $6(\mathrm{~S})$ & $7(\mathrm{~S})$ & $6(\mathrm{~S})$ & $6(\mathrm{~S})$ & $5(\mathrm{~S})$ \\
\hline BC-9896 & $5(\mathrm{~S})$ & $6(\mathrm{~S})$ & $6(\mathrm{~S})$ & $5(\mathrm{~S})$ & $6(S)$ & $7(S)$ \\
\hline BC-9992 & $5(\mathrm{~S})$ & $5(\mathrm{~S})$ & $6(\mathrm{~S})$ & $6(\mathrm{~S})$ & $5(\mathrm{~S})$ & $7(\mathrm{~S})$ \\
\hline BC-97005 & 4 (MS) & $5(\mathrm{~S})$ & $6(\mathrm{~S})$ & $6(\mathrm{~S})$ & $6(\mathrm{~S})$ & $5(\mathrm{~S})$ \\
\hline BC-99102 & $5(\mathrm{~S})$ & $5(\mathrm{~S})$ & $6(S)$ & $5(\mathrm{~S})$ & $5(\mathrm{~S})$ & $5(\mathrm{~S})$ \\
\hline BC-20151 & 4 (MS) & 4 (MS) & $5(\mathrm{~S})$ & $6(\mathrm{~S})$ & $5(\mathrm{~S})$ & 4 (MS) \\
\hline KG 9521 & 4 (MS) & 4 (MS) & $5(\mathrm{~S})$ & $5(\mathrm{~S})$ & $5(\mathrm{~S})$ & $5(\mathrm{~S})$ \\
\hline BC-9960 & 4 (MS) & $5(\mathrm{~S})$ & 4 (MS) & $5(\mathrm{~S})$ & $5(\mathrm{~S})$ & $5(\mathrm{~S})$ \\
\hline KG 9512 & $1(\mathrm{R})$ & $5(\mathrm{~S})$ & 4 (MS) & $5(\mathrm{~S})$ & $5(\mathrm{~S})$ & $2(\mathrm{R})$ \\
\hline BC-9942 & 4 (MS) & 4 (MS) & 4 (MS) & 4 (MS) & $5(\mathrm{~S})$ & 4 (MS) \\
\hline ВС-9999 & $1(\mathrm{R})$ & $5(\mathrm{~S})$ & 4 (MS) & 4 (MS) & 4 (MS) & 4 (MS) \\
\hline BC-9937-2-2 & $1(\mathrm{R})$ & 4 (MS) & 4 (MS) & $1(\mathrm{R})$ & 4 (MS) & 4 (MS) \\
\hline BC-9939-1 & 0 (HR) & 4 (MS) & 4 (MS) & 4 (MS) & 4 (MS) & 4 (MS) \\
\hline BS-9978 & $1(\mathrm{R})$ & 4 (MS) & 4 (MS) & 4 (MS) & $1(\mathrm{R})$ & 4 (MS) \\
\hline ВC-9993 & 0 (HR) & 4 (MS) & 4 (MS) & 4 (MS) & $1(\mathrm{R})$ & 4 (MS) \\
\hline BC-9998 & $1(\mathrm{R})$ & 4 (MS) & 4 (MS) & $1(\mathrm{R})$ & $1(\mathrm{R})$ & 4 (MS) \\
\hline BC-9937-2-1 & $1(\mathrm{R})$ & $1(\mathrm{R})$ & $1(\mathrm{R})$ & $1(\mathrm{R})$ & 4 (MS) & $1(\mathrm{R})$ \\
\hline BS-9979 & 0 (HR) & 4 (MS) & 4 (MS) & 0 (HR) & 4 (MS) & 0 (HR) \\
\hline BC-20140 & $1(\mathrm{R})$ & 4 (MS) & 3 (MR) & 3 (MR) & $2(\mathrm{R})$ & 3 (MR) \\
\hline KG 9515 & 0 (HR) & 0 (HR) & 0 (HR) & 0 (HR) & 0 (HR) & 0 (HR) \\
\hline
\end{tabular}

${ }^{a}$ Disease ratings based on a scale of 0 to 9 . $\mathrm{HR}=$ highly resistant $(0), \mathrm{R}=$ resistant (1-2), MR = moderately resistant (3), MS = moderately susceptible(4), $\mathrm{S}=$ susceptible(5-9). All data are the averages of two experiments with three replications each. 
entire leaves. These classes ranged from 10.0 to over $50.0 \%$ diseased leaf area. With this scale, classes 0 to 3 were considered indicative of resistant responses and classes 4 to 9 of susceptible responses. Leaf blight severity was recorded as the percentage of diseased leaf area. All data are the means of 10 plants infected by $B$. coicis with three replications. The experiment was conducted twice in a randomized complete design with similar results. Data represented are from two experiments.

The Statistical Analysis System for personal computers (SAS Institute Inc., Cary, NC) was used for all analyses of the data. Disease severity (percent diseased leaf area) from the two experiments in the greenhouse was analyzed statistically following the PROC analysis of variance procedure of SAS. Fisher's protected least significant difference at $P=0.05$ was applied to compare the virulence of all tested B. coicis isolates.

\section{RESULTS}

Virulence of $B$. coicis isolates was evaluated on the six adlay cultivars or lines of differing resistance under controlled environmental conditions. Leaf blight lesions became visible on the leaves of most adlay cultivars or lines within 48 to $60 \mathrm{~h}$ after inoculation with $B$. coicis at the two-leaf stage. Lesions consisted of two distinguishable symptoms: chlorosis and necrosis. Chlorosis was characterized by the development of diffuse and progressive yellowing in the adlay leaves. Necrosis was limited around a small, dark-brown spot in the tan-colored leaf tissue. The necrotic, dark-brown lesions did not expand and the fungus did not sporulate in them. The disease ratings were divided into 10 classes to evaluate infection levels in adlay seedling plants (Table 2; Fig. 1). A 10 -class rating scale was prepared based on the quantitative and qualitative differences of lesions observed on leaves of adlay cultivars or lines infected with isolates of $B$. coicis. Descriptions of disease development on adlay plants were based on the infection by isolate BC-9992 in the greenhouse, but almost all of the other isolates tested gave similar lesion types.

Although the type and size of the lesions on adlay leaves varied almost continuously during the development of leaf blight, five class infection types (highly resistant, resistant, moderately resistant, moderately susceptible, and susceptible responses) were distinguished on the quantitative and qualitative differences of lesions observed (Table 2). Disease rating class 0 was highly resistant response (HR), while classes 1 and 2 were characterized by resistant responses (R). Class 3 was indicative of moderately resistant response (MR). Moderately susceptible response (MS) was included as class 4, while classes 5 to 9 were susceptible responses $(\mathrm{S})$.

Virulence of the 33 isolates of B. coicis on the six adlay cultivars or lines was evaluated by a disease rating scale (Table 3 ). Significant differences in virulence were found among isolates of B. coicis, although the differences were quantitative rather than qualitative. Infection responses of the six adlay cultivars or lines to $B$. coicis varied among the isolates, ranging from 0 to 9. All isolates, except KG-9515, were pathogenic on adlay plants. In particular, isolates BC-20140, BC-9979, BC-9937-21, and BC-9998 were less virulent than the others. Isolate BC-98011 was highly virulent - capable of causing highly susceptible reactions on the six adlay cultivars or lines. Infection responses to all tested isolates ranged from 0 to 7 for Tsukuba B15, from 0 to 8 for Yulmu 1, and from 0 to 9 for Huksuk 2. Significant differences in resistance were found among adlay cultivars or

Table 4. Disease severity (percent diseased leaf area) on the second leaves of six adlay cultivars or lines inoculated by foliar spray with 33 isolates of Bipolaris coicis at the two-leaf stage

\begin{tabular}{|c|c|c|c|c|c|c|c|c|c|}
\hline \multirow[b]{2}{*}{ Isolate } & \multicolumn{7}{|c|}{ Percent diseased leaf area ${ }^{a}$} & \multirow[b]{2}{*}{$\mathbf{L S D}_{0.05}$} & \multirow[b]{2}{*}{ Rank } \\
\hline & Tsukuba B15 & Muzu & Yulmu 1 & Yonchon & Limgae & Huksuk 2 & Average & & \\
\hline BC-98011 & 13.5 & 12.0 & 17.5 & 22.5 & 32.5 & 64.0 & 27.0 & 1.6 & 1 \\
\hline ВC-9986 & 8.2 & 13.0 & 38.0 & 52.5 & 22.0 & 24.0 & 26.3 & 1.2 & 2 \\
\hline BC-9894 & 22.0 & 22.0 & 28.0 & 11.4 & 19.0 & 49.0 & 25.2 & 0.9 & 3 \\
\hline BC-9985 & 13.5 & 17.0 & 37.0 & 38.5 & 20.0 & 22.5 & 24.8 & 0.8 & 4 \\
\hline BC-9895 & 10.0 & 14.5 & 13.9 & 13.7 & 16.0 & 67.0 & 22.5 & 8.0 & 5 \\
\hline BC-97006 & 9.4 & 11.2 & 15.0 & 21.0 & 33.5 & 40.5 & 21.8 & 1.1 & 6 \\
\hline ВC-99101 & 14.4 & 17.0 & 18.5 & 28.0 & 30.5 & 22.0 & 21.7 & 0.4 & 7 \\
\hline BC-99103 & 21.5 & 16.7 & 16.6 & 18.7 & 13.1 & 16.0 & 17.1 & 0.3 & 8 \\
\hline ВC-9889 & 5.0 & 7.9 & 6.8 & 9.8 & 8.8 & 52.5 & 15.1 & 4.1 & 9 \\
\hline ВC-9973 & 8.9 & 12.5 & 10.8 & 11.7 & 26.5 & 19.0 & 14.9 & 0.9 & 10 \\
\hline BC-9940 & 5.8 & 22.5 & 15.0 & 17.5 & 17.5 & 9.4 & 14.6 & 0.7 & 11 \\
\hline BC-9957 & 3.0 & 7.0 & 10.2 & 12.0 & 10.6 & 45.0 & 14.6 & 1.1 & 12 \\
\hline BC-20136 & 8.1 & 9.1 & 12.4 & 16.2 & 17.7 & 19.2 & 13.8 & 0.7 & 13 \\
\hline BC-99100 & 6.4 & 15.0 & 17.0 & 15.0 & 11.0 & 9.8 & 12.4 & 0.4 & 14 \\
\hline BC-9896 & 7.3 & 10.5 & 12.0 & 8.0 & 14.2 & 18.5 & 11.8 & 0.9 & 15 \\
\hline ВC-9992 & 6.2 & 8.5 & 10.9 & 11.7 & 9.3 & 17.9 & 10.8 & 0.5 & 16 \\
\hline BC-97005 & 4.0 & 8.2 & 11.2 & 10.1 & 13.5 & 6.6 & 8.9 & 0.3 & 17 \\
\hline BC-99102 & 7.4 & 7.6 & 10.3 & 9.5 & 7.1 & 8.3 & 8.4 & 0.4 & 18 \\
\hline BC-20151 & 4.8 & 5.0 & 7.0 & 13.5 & 6.4 & 4.4 & 6.9 & 0.3 & 19 \\
\hline KG 9521 & 4.6 & 4.2 & 6.8 & 8.3 & 7.6 & 7.2 & 6.5 & 0.3 & 20 \\
\hline BC-9960 & 3.4 & 7.0 & 5.0 & 5.4 & 6.0 & 8.2 & 5.8 & 0.2 & 21 \\
\hline KG 9512 & 1.8 & 5.6 & 5.0 & 5.2 & 5.8 & 1.6 & 4.2 & 0.2 & 22 \\
\hline BC-9942 & 2.6 & 3.8 & 2.6 & 4.0 & 6.0 & 4.6 & 3.9 & 0.2 & 23 \\
\hline ВC-9999 & 1.2 & 6.2 & 3.8 & 3.3 & 3.4 & 3.4 & 3.6 & 0.2 & 24 \\
\hline BC-9937-2-2 & 1.0 & 4.6 & 3.4 & 1.8 & 3.4 & 4.2 & 3.1 & 0.2 & 25 \\
\hline ВС-9939-1 & 0.0 & 3.8 & 3.4 & 4.6 & 3.8 & 2.2 & 3.0 & 0.2 & 26 \\
\hline BS-9978 & 1.4 & 3.0 & 2.6 & 2.6 & 1.0 & 3.4 & 2.3 & 0.2 & 27 \\
\hline ВC-9993 & 0.0 & 2.6 & 3.0 & 2.6 & 1.8 & 2.6 & 2.1 & 0.1 & 28 \\
\hline BC-9998 & 1.3 & 2.2 & 2.6 & 1.8 & 2.0 & 2.4 & 2.1 & 0.1 & 29 \\
\hline BC-9937-2-1 & 1.0 & 1.6 & 1.4 & 1.0 & 2.4 & 1.4 & 1.5 & 0.2 & 30 \\
\hline BS-9979 & 0.0 & 3.0 & 2.2 & 0.0 & 2.4 & 0.0 & 1.3 & 0.2 & 31 \\
\hline BC-20140 & 1.0 & 2.2 & 1.0 & 1.5 & 1.0 & 1.2 & 1.3 & 0.1 & 32 \\
\hline KG 9515 & 0.0 & 0.0 & 0.0 & 0.0 & 0.0 & 0.0 & 0.0 & 0.0 & 33 \\
\hline Average & 6.0 & 8.7 & 10.6 & 11.6 & 11.4 & 16.8 & $\ldots$ & $\ldots$ & $\ldots$ \\
\hline $\mathrm{LSD}_{0.05}$ & 0.4 & 0.8 & 0.8 & 1.1 & 0.7 & 1.2 & $\ldots$ & $\ldots$ & $\ldots$ \\
\hline
\end{tabular}

a All values of percent leaf area diseased were determined 7 days after inoculation. All data are the averages of two experiments with three replications each. Values were statistically analyzed according to Fisher's protected least significant difference test (LSD) $(P=0.05)$. 
lines. All cultivars or lines tested were resistant to certain isolates tested.

Virulence of the isolates of $B$. coicis on the six adlay cultivars or lines also was evaluated by disease severity that was expressed as percent leaf area diseased (Table 4). Significant differences were found in disease severity values of the six adlay cultivars or lines. Disease severities were lowest on Tsukuba B15 throughout most of the isolates, but highest on Huksuk 2. However, the levels of disease severity varied among the six adlay cultivars or lines. The rankings of adlay cultivars by disease severity were similar to each other. The most resistant line was Tsukuba B15, with a mean of 6 in a range of 0 to 22, and Yulmu 1, with a mean of 10.6 in a range of 0 to 38 , while Huksuk 2, with a mean of 16.9 in a range of 0 to 67 , was the most susceptible. Based on the differences in disease severity values, the relative ranks tance were (in order) Tsukuba B15 $>$ Muzu $>$ Yulmu $1>$ Limgae $>$ Yonchon $>$ Huksuk 2. All isolates except KG-9515 were pathoof adlay cultivars or lines in levels of resis-

genic on adlay plants. Isolate BC-98011 was highly virulent - capable of causing highly susceptible reactions on the six adlay cultivars or lines. However, isolates BC-9937-2-1, BC-9979, and BC-20140 were less virulent than the other isolates. The analysis of variance for disease severities (percent diseased leaf area) obtained in the two experiments showed highly significant differences among isolates, cultivars, and cultivar-isolate interactions (Table 5). The adlay cultivars and the $B$. coicis isolates in the two experiments interacted differentially when inoculated with each of $33 \mathrm{~B}$. coicis isolates. However, there were no significant differences in disease severity among experiment, experiment-isolate interactions, and experiment-cultivar-isolate interactions.

There was, in general, no differential interaction between adlay cultivars or lines and B. coicis isolates when the three cultivars or lines Tsukuba B15, Yulmu 1, and Huksuk 2 of differing resistance were inoculated with each of the isolates BC-9992 and BC-99103 (Fig. 2). However, the line

Table 5. Analysis of variance for disease severity (percent diseased leaf area) of six cultivars or lines inoculated with 33 isolates of Bipolaris coicis

\begin{tabular}{lrccc}
\hline Source of variation & df & Mean square & $\boldsymbol{F}$ value & $\boldsymbol{P}$ \\
\hline Experiment & 1 & 99.2 & 0.98 & 0.3224 \\
Isolate & 32 & $2,586.9$ & 25.56 & $<0.01$ \\
Cultivar or line & 5 & $3,523.3$ & 34.81 & $<0.01$ \\
Experiment-isolate & 32 & 99.1 & 0.98 & 0.5019 \\
Experiment-cultivar or line & 5 & 100.0 & 0.99 & 0.4237 \\
Cultivar or line-isolate & 160 & 438.9 & 4.34 & $<0.01$ \\
Experiment-cultivar or line- & 160 & 97.9 & 0.97 & 0.5951 \\
$\quad$ isolate & & & &
\end{tabular}
isolate

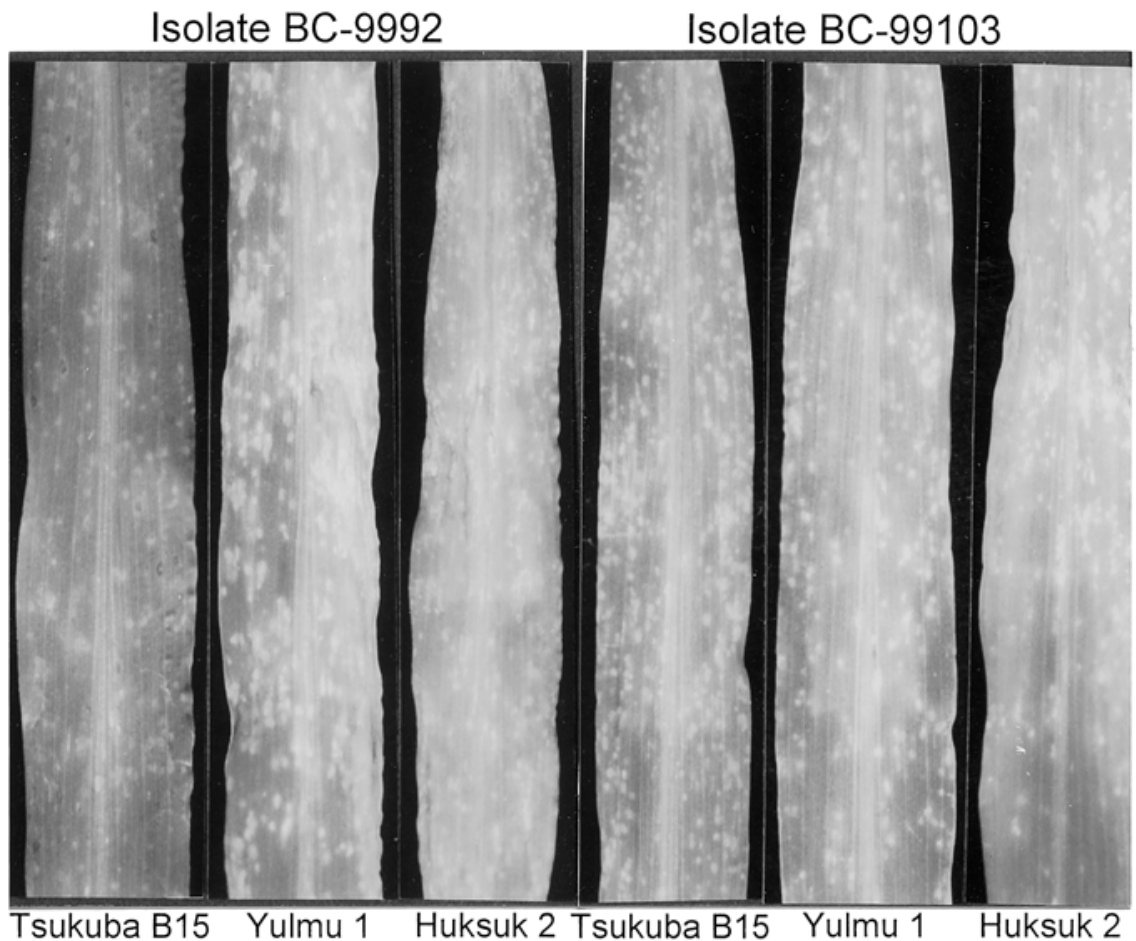

Fig. 2. Different infection responses of adlay cultivars or lines Tsukuba B 15, Yulmu 1, and Huksuk 2 to the isolates BC-9992 and BC-99103 of Bipolaris coicis at the two-leaf stage.
Tsukuba B15 showed typical resistant reactions to the two isolates, whereas Yulmu 1 and Huksuk 2 were susceptible to the two isolates. At 7 days after inoculation, lesions of leaf blight on adlay leaves of Tsukuba B15 were different in shape (i.e., small, dark-brown spots for isolate BC-9992, but small, white-brownish spots for isolate BC-99103). In the susceptible Yulmu 1 and Huksuk 2, some parts of the diseased leaves with chlorotic or necrotic lesions were coalesced.

\section{DISCUSSION}

To precisely assess the virulence of $B$. coicis isolates in the present study, a rating scale of disease reactions for adlay seedlings to B. coicis was developed based on the type and size of lesions observed on adlay leaves. The use of a disease rating scale enabled us to evaluate virulence to adlay of Korean isolates of B. coicis from diverse geographic origins. The 10-class disease rating scale was classified based on the qualitative (presence of necrosis and chlorosis) and quantitative (percent leaf area diseased) traits of lesions, which are illustrated in color plates (Fig. 1). The disease rating scale could be used as a guide to readily estimate the type and relative size of lesions on adlay cultivars or lines when needed for the classification of infection types of leaf blight. Similar disease rating scales have been developed for barley net blotch (23) and wheat tan spot diseases (13). The disease rating scales have been very useful in many studies of the respective pathosystems $(5,15)$. For instance, 45 pathotypes from 182 isolates of Pyrenophora teres were identified using nine differential host lines (24). The pathotype classification scheme used by Lamari and Bernier (14) to describe variation in the pathogen is still being used to group isolates of $P$. tritici-repentis on the basis of symptoms produced on hexaploid wheats. Recently, Fetch and Steffenson (7) developed a nine-class rating scale diagram of spot blotch for assessing the infection responses of barley seedlings to Cochliobolus sativus.

The virulence of 33 isolates of B. coicis from diverse geographic origins was evaluated on six adlay cultivars or lines under controlled environmental conditions. The greenhouse evaluation of virulence of $B$. coicis isolates to adlay cultivars or lines worked well not only to develop the disease rating scale but also to assess the pathogenic variation of $B$. coicis isolates, because the infection responses of adlays were almost identical to those observed in the adlay-growing fields. B. coicis reproduces primarily by asexual means in nature, but its teleomorph was not found in adlay fields $(21,25)$. Recently, Kim et al. (12) reported the pathogenic variation of $B$. coicis on adlay plants in Korea, indicating that the pathogenic specificity of the fungus may operate horizontally rather than 
vertically. These data were well supported by previous observations of the variation in virulence of some leaf blight fungi of adlay in Korea (11).

The characterization of pathogenic variation of B. coicis isolates and their distribution may be valuable for breeding programs of adlay cultivars for resistance to leaf blight. Moreover, this data can provide more information for the study of the genetics of adlay-B. coicis interactions. Significant differences in virulence on adlay plants were detected among isolates of $B$. coicis. Isolate BC-98011, which showed a high level of virulence on the line Tsukuba $\mathrm{B} 15$, was most virulent to all cultivars or lines tested. In particular, isolates BC9937-2-1, BC-9979, and BC-9998 were less virulent than the other isolates tested. Ratings of disease reactions to all tested isolates ranged from 0 to 7 for Tsukuba $\mathrm{B} 15$, from 0 to 8 for Yulmu 1, and from 0 to 9 for Huksuk 2. Similarly, variation in the virulence of $B$. coicis has been demonstrated in a previous study of adlay cultivars or lines (12). However, there was no significant correlation between geographical origin and collection year in the virulence of B. coicis isolates. Interestingly, isolate KG 9515, which had been isolated in 1995 from Yongdong area of Korea, did not infect all tested adlay cultivars or lines (Tables 3 and 4), which suggests that a long-term maintenance of $B$. coicis isolates in artificial culture media such as corn meal agar may result in the loss of their pathogenicity on adlay plants.

The line Tsukuba B15 was most resistant to leaf blight throughout most isolates, and Huksuk 2 was most susceptible. However, there were no differential interactions between $B$. coicis isolates and adlay cultivars or lines. Based on the differences in the disease rating scale and leaf blight severity values, the relative ranks of cultivar or lines in levels of resistance were (in order) Tsukuba B15 > Muzu > Yulmu $1>$ Yonchon $>$ Limgae $>$ Huksuk 2 (Tables 2 and 3). Disease responses to leaf blight were not distinguished among four adlay cultivars or lines, except Tsukuba B15 and Huksuk 2. The ranking of the six adlay cultivars or lines for resistance to leaf blight was very similar to the results of previous field experiments $(1,2)$. However, more detailed studies will be necessary to test these adlay cultivars at a number of locations to look for variable responses to leaf blight and also to select a B. coicis isolate capable of separating adlay cultivars in the greenhouse in such a way as to predict field performance.

The classification of crops into the resistant and susceptible categories is an important consideration in the selection of breeding lines resistant to disease $(16,20)$. Percent diseased leaf area usually has been used to assess reactions of adlay cultivars or lines to leaf blight $(1,2,12)$. In our present study, there seemed to be some differences between the ratings of disease development (Table 3) and the percent diseased leaf area on adlay plants (Table 4). For example, isolate BC-20136 was highly virulent by the disease rating scale but not by percent diseased leaf area. Accordingly, percent diseased leaf area may not be the most reliable parameter for determining the resistance levels of adlay cultivars to leaf blight, because of the lack of assessing qualitative disease responses. In particular, it is important to develop an easy and objective rating method for classification of the disease reactions of adlay cultivars or lines to $B$. coicis in breeding programs. The disease rating scale developed in this study was qualitative as well as quantitative, based on the lesion size and type (Table 2). Quantitative aspects of lesion sizes also were considered in the disease rating scale, including a relative or comparative sense (e.g., lesions of class 8 are relatively larger than lesions of class 7). The disease rating scale illustrated in Figure 1 may be a useful criterion to evaluate a large number of adlay cultivars or lines for the infection responses to leaf blight. The classified disease rating scale was not intended to be a rigid or fixed criterion. Rather, it provided supplemental information for reliable infection type classes.

\section{LITERATURE CITED}

1. Chang, S. W., and Hwang, B. K. 2002. Relationship of host genotype to Bipolaris leaf blight severities and yield components of adlay. Plant Dis. 86:774-779.

2. Chang, S. W., and Hwang, B. K. Effects of plant age, leaf position, inoculation density and wetness period on Bipolaris coicis infection in adlays of differing resistance. Plant Dis. In press.

3. Chang, S. W., Kim, H. D., and Jeon, D. H. 2000. Effects of seed disinfectant treatments on leaf blight and smut disease in Coix lachryma-jobi L var. ma-yuen. Korean. J. Med. Crop Sci. 8:79-82.

4. Cook, R. J., and Timian, R. G. 1962. Lesion type as a means of detecting resistance in barley leaves to the spot blotch Helminthosporium. Phytopathology 52:1086-1089.

5. da Luz, W. C., and Hosford, R. M., Jr. 1980. Twelve Pyrenophora trichostoma races for virulence to wheat in the central plains of North America. Phytopathology 70:11931196.

6. Fetch, T. G., Jr., and Steffenson, B. J. 1994. Identification of Cochliobolus sativus isolates expressing differential virulence on two-row barley genotypes from North Dakota. Can. J. Plant Pathol. 16:202-206.

7. Fetch, T. G., Jr., and Steffenson, B. J. 1999. Rating scales for assessing infection responses of barley infected with Cochliobolus sativus. Plant Dis. 83:213-217.

8. Freppon, J. T., Lipps, P. E., and Pratt, R. C. 1994. Characterization of the chlorotic lesion response by maize Cercospora zeae-maydis. Plant Dis. 78:945-949.
9. Honkura, R., Oikawa, T., and Inoue, T. 1982 Studies on diseases of Job's tears. I. Influence of cultivation method on occurrence of Job's tears leaf blight. Annu. Rep. Plant Prot. N. Jpn. 33:53-54.

10. Jain, S. K., and Banerjee, D. K. 1974. Preliminary observations on the ethnobotany of the genus Coix. Econ. Bot. 28:38-42.

11. Kim, J. S., and Lee, D. H. 1998. Seed transmission of Bipolaris coicis, B. cynodontis, B. maydis and Curvularia lunata causing leaf blight of Job's tears. Korean J. Plant Pathol. 14:287-293.

12. Kim, S. K., Kim, K. W., Hong, S. S., Park, E. W., Yang, J. S., and Kim, Y. J. 1997. Isolation and identification of Bipolaris coicis, causing leaf blight of Job's tears. Korean J. Mycol. 25:291-296.

13. Lamari, L. R., and Bernier, C. C. 1989 Evaluation of wheat lines and cultivars for reaction to tan spot (Pyrenophora tritici-repentis) based on lesion types. Can. J. Plant Pathol. 11:49-56.

14. Lamari, L. R., and Bernier, C. C. 1989. Virulence of isolates of Pyrenophora tritici-repentis on 11 wheat cultivars and cytology of the differential host reactions. Can. J. Plant Pathol. 11:284-290.

15. Lamari, L. R., Boulif, S. M., and Bernier, C. C. 1995. Identification of a new race in Pyrenophora tritici-repentis implications for the current pathotype classification system. Can. J. Plant Pathol. 17:312-318.

16. Lamari, L. R., Gilbert, J., and Tekauz A. 1998. Race differentiation in Pyrenophora tritici-repentis and survey of physiologic variation in western Canada. Can. J. Plant Pathol. 20:396400.

17. Lee, H. S., Park, K. J., Kim, K. J., and Yi, E S. 1997. Effects of field topography, ridge shape and crop rotation on growth and yield in Coix lachryma var. ma-yuen Stapf. Korean J. Med. Crop Sci. 5:162-166.

18. Lee, N. O. 2000. Genetic diversity of Bipolaris coicis causing leaf blight of Job's tears. M. S. thesis. Seoul National University, Suewon, Korea.

19. Luttrell, E. S. 1969. Curvularia coicis and the nodulosa group of Bipolaris. Mycologia 61:1031-1040.

20. Nutter, F. W., and Pederson, V. D. 1985. Receptivity, incubation, period, and lesion size as criteria for screening barley genotypes for resistance to Pyrenophora teres. Phytopathology 75:603-606.

21. Sivanesan, A. 1987. Graminiclolus Bipolaris, Curvularia, Drechslera, Exserohilum, and their teleomorph. Pages 54-55 in: Mycological Papers. CAB International Mycological Institute, Surrey, England.

22. Steffenson, B. J., and Webster, R. K. 1992 Pathotype diversity of Pyrenophora teres f. sp. teres on barley. Phytopathology 82:170177.

23. Tekauz, A. 1985. A numerical scale to classify reactions of barley to Pyrenophora teres. Can. J. Plant Pathol. 7:181-183.

24. Tekauz, A. 1990. Characterization and distribution of pathogenic variation in Pyrenophora teres $\mathrm{f}$. sp. teres and $P$. teres $\mathrm{f}$. sp. maculata from western Canada. Can. J. Plant Pathol. 12:141-148.

25. Tsuda, M., and Ueyama, A. 1977. Pseudocochliobolus nisikadoi, the perfect state of Helminthosporium coicis. Mycologia 69:11091120.

26. Valjavee-Gratian, M., and Steffenson, B. J. 1997. Pathotypes of Cochliobolus sativus on barley in North Dakota. Plant Dis. 81:12751278 . 